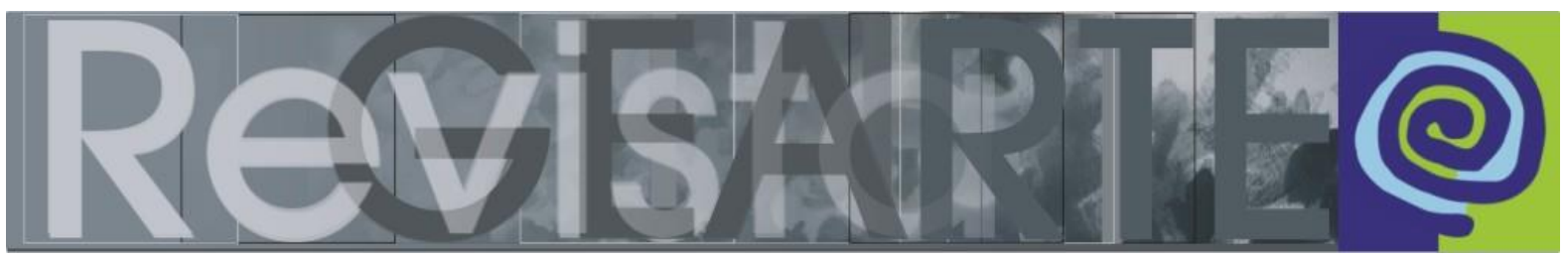

ISSN 2357-9854 | e-ISSN 2596-3198 (online)

\title{
Ensino de artes visuais e artesania: experiências, confluências e derivas
}

O conteúdo apresentado nesta edição da Revista GEARTE se inscreve em uma genealogia que percorre grande parte da hierarquia que articulou algumas das dualidades dominantes nas artes, como a prática profissional e a educação que está ligada às artes: artes maiores e menores, alta e baixa cultura, educação artística e artesania, faculdades de belas artes e escolas de artes e ofícios, cultura popular e cultura artística, etc. Tais dualidades levam Freitag (2015) a resenhar a obra de Shiner (2004) e fazer uma distinção muito clara entre o que é considerado arte, logo obra de arte, e o que se considera artesania, logo arte popular, artesanato e manualidades.

Embora as origens dessa diferenciação, como em quase tudo do ponto de vista ocidental, estejam na Grécia (arte versus técnica), foi durante a Renascença europeia que essa divisão adquiriu pleno significado ao moldar a diferença na qualidade produtiva e na hierarquia social entre o artista e o artesão. Mas a articulação estrutural, que em grande parte perdura até o presente, se dá sob a influência das políticas da llustração, que, de acordo com os modos de produção do capital e o sentido simbólico do valor (material e simbólico), foram promovidas por algumas elites do final do século XVIII, tanto na Europa quanto nas colônias americanas. Essa articulação favorece, como nos lembra Aurora Fernández Polanco (2019, p. 94),

la radical separación entre las artes que muestran de forma meridiana la división del trabajo: por un lado, las Bellas Artes, donde se preparan las 'almas bellas' para mejor gloria y representación de las naciones; por otro, 'las artes aplicadas', desde donde se procuraba remontar la economía.

Um bom exemplo da associação do artesanal com a economia pode ser visto no impulso dado à formação de artesãos em habilidades artísticas no século XVIII, que, no caso da Espanha, se reflete nas propostas de Jovellanos e, em particular, de Pedro Rodríguez Campomanes (1991), que em 1774 publicou o Discurso sobre el fomento de la industria popular e no ano seguinte, Educación PEIXE, Rita Inês Petrykowski; HERNÁNDEZ-HERNÁNDEZ, Fernando; PRIETO VILLANUEVA, Jesús-Ángel; 428 CANÔNICA, Rosangela. Ensino de artes visuais e artesania: experiências, confluências e derivas. 


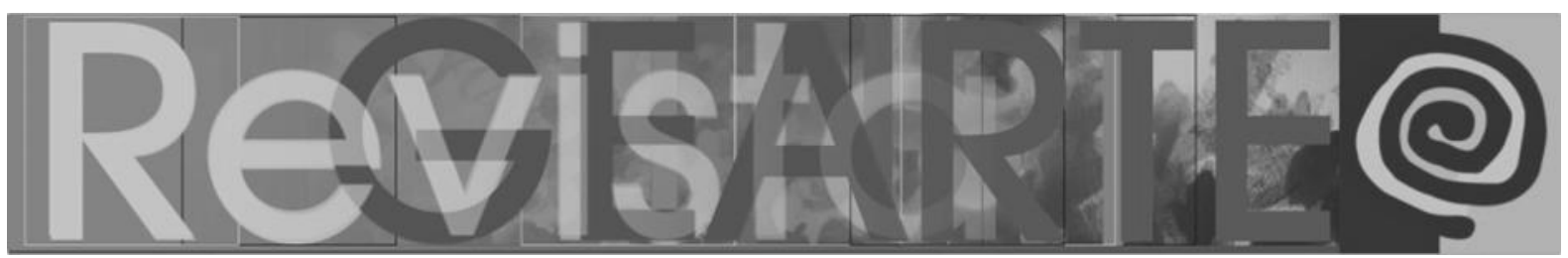

popular de los artesanos. Um reflexo dessa apreciação das artes/artesanias pode ser encontrado nos desenhos feitos em Valência para a produção das sedas manufaturadas que fazem parte do vestuário e dos estofados de móveis e salas e sua produção para exportação para as colônias, em vez de comprá-las em Paris ou Londres.

Essa separação/relação entre arte-artesania tem sido mantida até hoje com algumas exceções, como o movimento Arts \& Crafts, que foi gerado na GrãBretanha no século XIX em torno de William Morris e que se espalhou para cidades europeias e americanas. Deve-se lembrar que esse movimento surgiu como uma reação à industrialização e ao início da produção em massa, como uma tentativa moral de recuperar o significado da produção artesanal em oposição à produção mecanizada. Esse movimento reflete a rejeição e os medos gerados pela fábrica e pela industrialização e é projetado na recuperação de uma arte gótica idealizada — de base artesanal - , que podemos encontrar no trabalho de Gaudí e de outros arquitetos modernistas. Modernismo foi o nome dado à Art Noveau na Catalunha, que resgata 0 valor do artesanal - e do artesão - nas diferentes facetas decorativas e construtivas de suas produções.

No século passado, o ideal da Bauhaus também recupera o sentido do artesanal e o transfere para projetos arquitetônicos e projetos de objetos do cotidiano. Entretanto, essas reações, que geram lacunas no mundo das artes plásticas, não foram, como assinala Bea Espejo (2020, s.p.), "lo suficientemente grande para un museo y un mercado atento siempre a aires nuevos". Por essa razão, essas reações que põem em relação as artes e os ofícios, que tentam entrecruzá-los, têm sido obscurecidas (desfocadas ou diluídas) desde a segunda metade do século passado, pela própria configuração do sistema de arte. Como Bea Espejo (2020, s.p.) aponta, "Algunos veían en lo artesano la antítesis de lo mecánico, que por aquel entonces se había convertido en el estandarte de futuro. Un oficio anticuado al que se añadía el tinte de lo doméstico y lo femenino, que siempre andaba en penumbra mediática". 


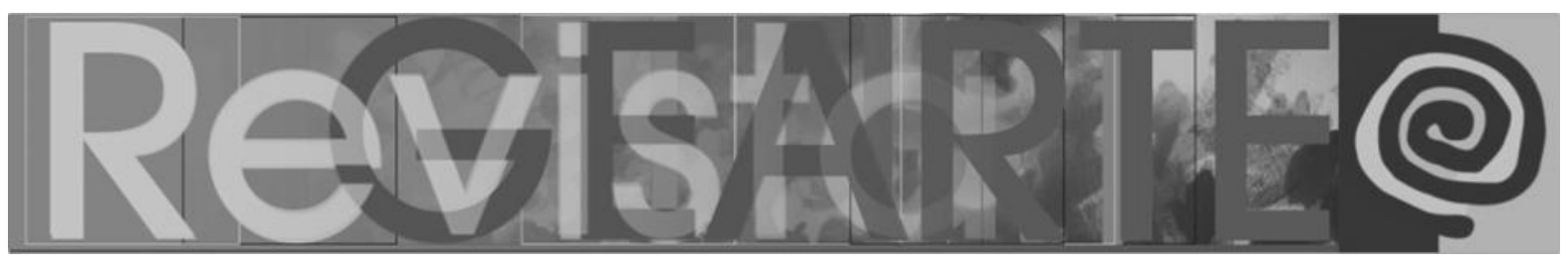

Entretanto, a partir da entrada no presente milênio, uma nova era começa a ser desenhada, com uma articulação entre arte/artesania, que tem algumas singularidades que a diferenciam das ações passadas. Agora não é um vínculo econômico, nem um projeto de regeneração estética da sociedade. A dualidade artesania e arte é diluída na medida em que as práticas artísticas tomam o artesanal, não como suporte da arte ou como uma forma de expandir o campo da arte. Essa é uma mudança na ontoepistemologia e na práxis da arte. O que está em jogo são ações que buscam, "no de establecer una Academia de las Artes que establezca una nueva unión entre dos mitades escindidas (artes bellas y oficios)", más tratá-las, como propõe Fernández Polanco (2019, p. 98), a partir de "una dinámica que repiense un proceso de reconversión estética, política, ecológica y epistémica" que para Bea Espejo (2020) implica uma reivindicação da artesania como uma ideologia artística que vai além dos ofícios. A artesania volta, mais uma vez, a ocupar o centro da prática de muitos artistas que reivindicam o manual como uma nova ideologia para além da artesania.

Nos permitimos formular algumas hipóteses que propõem linhas de investigação para ajudar a entender o surgimento dessa articulação das artes como artesania, ou como se preferir, do artesanal como artístico. Antes de mais nada, deve-se notar que esse movimento se manifesta em uma ampla presença de mulheres. Isso torna possível supor que o resgate do ofício artesanal como prática artística deve ser visto como uma resposta, ao mesmo tempo que irônica, militante e reivindicativa diante dessa longa tradição de excluir as mulheres da centralidade do sistema artístico, confinando-as à esfera doméstica. As trajetórias existentes estão sendo reavaliadas e revalorizadas, como as de Françoise Grossen (1943), artista têxtil conhecida por suas esculturas de cordas trançadas; Sheila Hicks (1934), cujo trabalho foi apresentado no Pompidou de Paris em uma exposição em 2018; Anni Albers (1899-1994), cujo trabalho foi exposto na Tate de Londres em 2018-2019. Esse centro de arte tem uma exposição pendente de outra pioneira, Magdalena Abakanowicz (1930-2017). 


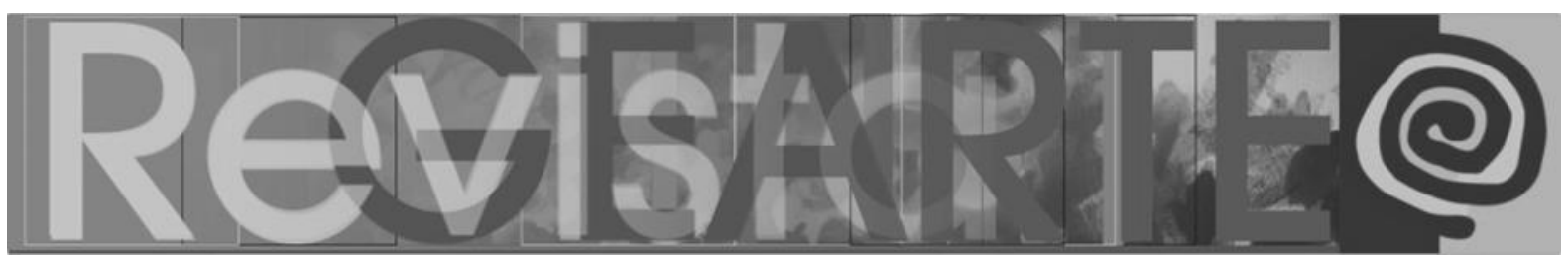

Devemos considerar também Ruth Asawa (1926-2013), cujas esculturas inspiradas na cestaria mexicana são uma referência para essa ponte à qual nos referimos. Três exposições mostram, enquanto escrevemos estas páginas, a vitalidade desta proposta: Making Knowing: Craft in Art, 1950-2019, no Museu de Arte Whitney, em Nova York (até o final de 2020 e onde a obra de Asawa é uma de suas principais atrações); a exposição com duas peças da artista mexicana Pia Camil (1980) intitulada Velo Revelo, no Clark Art Institute em Williamstown (Estados Unidos, até 3 de fevereiro de 2021) e Arts \& Crafts: Between Tradition, Discourse and Technologies na Kestner Gesellschaft em Hannover (2 de outubro a 10 de janeiro de 2021). Além destas artistas/artesãs, devemos mencionar também Rosemarie Trockel, Leonore Tawney, Eva Hesse, Grayson Perry.

No segundo semestre de 2019 (de 17 de setembro a 3 de novembro) foi realizada em Madrid a oitava edição da Bienal Internacional de Arte Têxtil Contemporânea WTA, sob o lema Cidade Sustentável, que reuniu artistas de 75 nacionalidades, totalizando a presença de 25 países dos cinco continentes, nos diferentes espaços expositivos. Entre eles, a presença de Judith Scott, Paloma Navares, Marisa González e Aurèlia Muñoz Ventura. Nesta mostra, expondo seu trabalho artístico e tendo sido uma das artistas premiadas, estava Lucia Loren, que nesta edição da Revista GEARTE nos apresenta parte de sua produção, por meio de um dos Ensaios Visuais aqui incluídos. Também em Madrid houve a Exposição TraMares: um recorte do têxtil brasileiro, na Casa Brasil, país homenageado por esta Bienal. Vinte e um artistas participaram dessa exposição, entre eles Zorávia Bettiol, Renata Meirelles, Marta Meyer, Veronica Filipak, Marina Godoy, Ilca Barcellos.

No Brasil temos uma grande variedade de nomes que propõem essa fusão entre arte e artesania, entre eles a forte expressão de Lygia Clark, com suas obras sensoriais, cujo projeto político transborda e traz o popular para um contexto artístico, sem separá-lo ou dicotomizá-lo. Adriana Varejão nas narrativas dos azulejos, alguns feitos a partir de peças de cerâmica e de pratos, remodelados e 


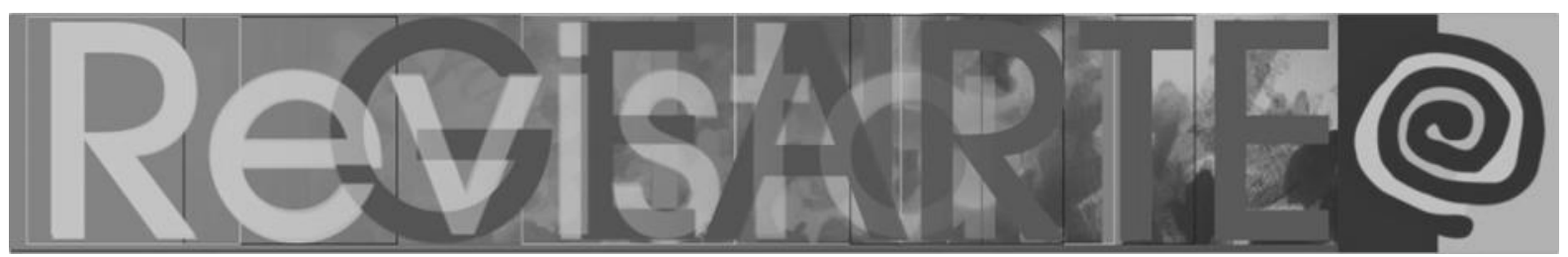

pintados; ou Vera Chaves Barcellos, propondo suas paisagens epidérmicas; também a obra de Leda Catunda, que reflete superfícies singulares e materiais não convencionais, em uma poética que amplia os limites da pintura; ou ainda a jovem artista Yuli Yamagata, que se move entre composições, volumes, esculturas, artesanias e costuras, por meio da estranheza das formas, entre tantos artistas.

Nesta extensa lista também podemos incluir Ernesto Neto, Mike Kelley, Jorge Pardo, Arthur Bispo do Rosário, Cildo Meireles, Tunga, Vik Muniz, José Leonilson, Alexandre Heberte, Helio Oiticica, Denilson Baniwa, entre outros. Entretanto, é um movimento no qual as mulheres têm um papel preponderante. Mulheres que fazem parte de uma nova geração de artistas que, usando variedade e fusão de formatos, como aponta Bea Espejo (2020, s.p.), ao mesmo tempo "disloca (n) cualquier tipo de lógica cronológica". Onde o ofício, ao possibilitar uma "acumulación desorganizada de elementos" que parecem "imitar la contradictoria función de la mente humana" como nos vasos de Milea Muzquiz (1927); ou em como a arte/artesania é projetada como expressão da identidade cultural em um mundo globalizado nas obras de Azra Aksamija (1976) ou Olaf Holzapfel (1969). Esse percurso esboça que, especialmente entre as mulheres, a artesania é recuperada de forma difusa, profusa e entrelaçada, senão como um outro sentido da arte, que desenha um relato sobre a arte e o artista, projetando um lugar próprio que está ligado a outras genealogias e resgatando espaços localizados nas margens do sistema da arte.

Esta última referência abre uma segunda hipótese, que pode confrontar a relação entre arte/artesania com uma resposta ao desastre ecológico, na forma do que Aurora Fernández Polanco (2019, p. 96) vê como uma "reconversão" que trata "de retomar los 'oficios' del lado de la buena vida y no al servicio de la producción". As propostas da Pia Camil (1980) falam da decomposição da paisagem urbana mexicana, ao mesmo tempo em que fazem uma crítica ao consumismo. Seus têxteis, como assinala Bea Espejo (2020, s.p.), "siempre están en el límite de la rasgadura para cuestionar la fragilidad de lo que nos sostiene y lo que nos 


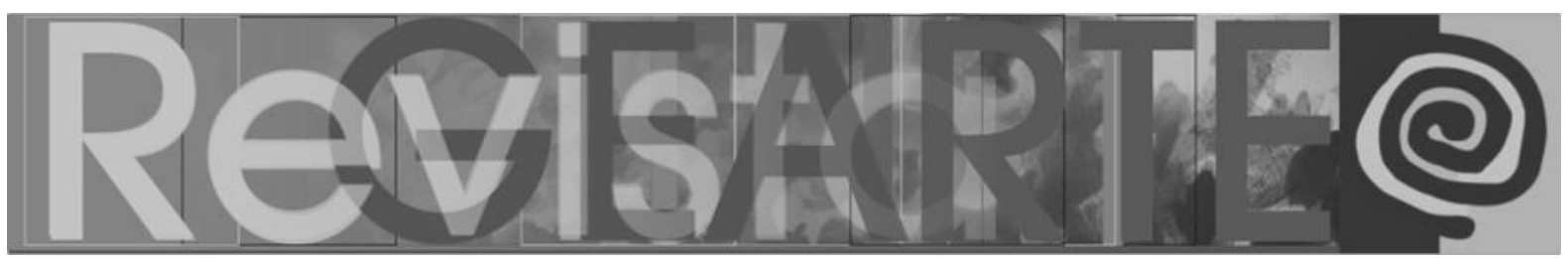

mantiene unidos". Algo que também é levantado por Josep Maynou (1980) quando relaciona performances, têxteis, desenho e instalações, diante da abordagem de uma grande variedade de objetos de consumo popular e práticas sociais da cultura popular. Isso novamente abre a porta para questionar a divisão e a hierarquia entre alta e baixa cultura.

A terceira hipótese está ligada à chamada de atenção de Bea Espejo (2000), que nos lembra que o sistema da arte, como parte do sistema capitalista, tem uma tendência a fagocitar e aproveitar tudo o que emerge como novo. Esse sistema tem uma longa experiência na integração de qualquer movimento que possa aparecer nas periferias ou nas margens, especialmente se vislumbrar alguma forma de rentabilidade. Esta é a razão da chamada de atenção que esta autora nos deixa:

\begin{abstract}
Con el \#MeToo tras la oreja del museo y la reivindicación de los oficios entre la generación más joven de artistas, la artesanía abraza un estatus renovado en el mundo del arte. En los últimos años, ha pasado de ser una pieza de mal encaje a una vía de escape. Pocos campos están más revalorizados, incluso más allá de lo artístico. Es el negocio perfecto. El nuevo lujo. $Y$ hay porqués. En un momento de inquietud colectiva, el trabajo manual proporciona un ancla firme. Es minucioso, regular y preciso. Nos da algo en lo que creer. Lo complicado convertido en posibilidad. Un campo mental conocido y un tiempo pausado, consciente y genuino alejado de la habitual ansiedad de la vida contemporánea (ESPEJO, 2000, s.p.)
\end{abstract}

Tudo isso nos ajuda a situar as contribuições desta edição da GEARTE em coordenadas mais amplas, que nos permitem intuir a profundidade do deslocamento que acompanha o movimento - entendido, não no sentido canônico da história da arte, senão como deslocamento que torna possível outras relações, olhares e encontros - de arte/artesania. Mas a proposta que se abre aqui também procura ser, como aponta Silvia Rivera Cusicanqui (1986, p. 36), uma alternativa à "la comunidad-mapa" (que geralmente é a visão dos homens, mais conceitual), mediante a "la comunidad-tejido" (que tende a ser a visão das mulheres) para que se gere "una nueva praxis de producción y circulación de saberes prácticos y 


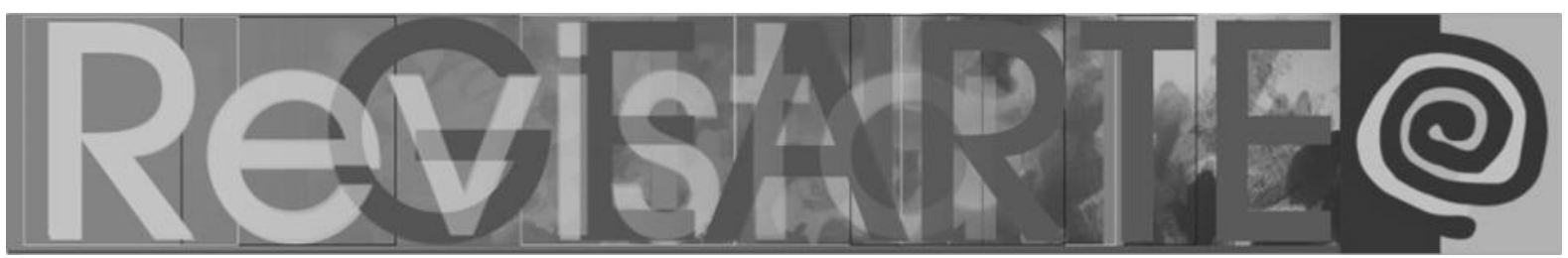

productivos tanto como éticos y organizativos", um deslocamento que também pode afetar a forma como as artes são consideradas e orientadas na educação.

\section{Arte/artesania e a ampliação dos espaços para a educação por meio das artes}

Uma das funções sociais das artes na educação (em sentido amplo, e não apenas na escola) tem sido a de transmitir e perpetuar os dualismos e hierarquias destacados na primeira parte deste artigo. Conhecer e valorizar os artistas (brancos e ocidentais) do cânone que foi tecido na narrativa dominante da história da arte tem sido sua função principal tanto nas referências que são exibidas em museus e centros de arte quanto naquelas que aparecem em livros educativos ou nas propostas que são realizadas em oficinas de arte. O aprendizado e a valorização das produções relacionadas às belas artes ocidentais tem sido $-\mathrm{e}$ continua a ser - a tendência dominante. Isto levou - e continua levando - à exclusão do que não faz parte dessa herança. O que supõe deixar de lado, ou reduzir ao anedótico e circunstancial, tudo o que está à margem dessa corrente poderosa e dominante.

Nos casos em que o periférico ocupa alguma forma de centralidade, é porque ele pode ser reconhecido dentro do sistema hegemônico (foi formado ou reside em cidades ocidentais ou ocidentalizadas ou é reconhecido em seu trabalho como refletindo as categorias artísticas da história da arte ocidental) ou confirma as visões geoestratégicas dos ocidentais. Mesmo em organizações de arte/educação que deveriam ser inclusivas, como InSEA, até recentemente se surpreendia quando os poucos colegas africanos que participavam de seus encontros, reivindicavam que a artesania era sua genuína forma de arte/educação, na medida em que seu significado simbólico os vinculava aos relatos que os constituíam diante das práticas colonizadoras. Essa relação entre a artesania e seu significado simbólico é algo que é excluído quando o artesanal está ligado, sem nuances, ao trabalho manual como uma experiência artística na educação. 


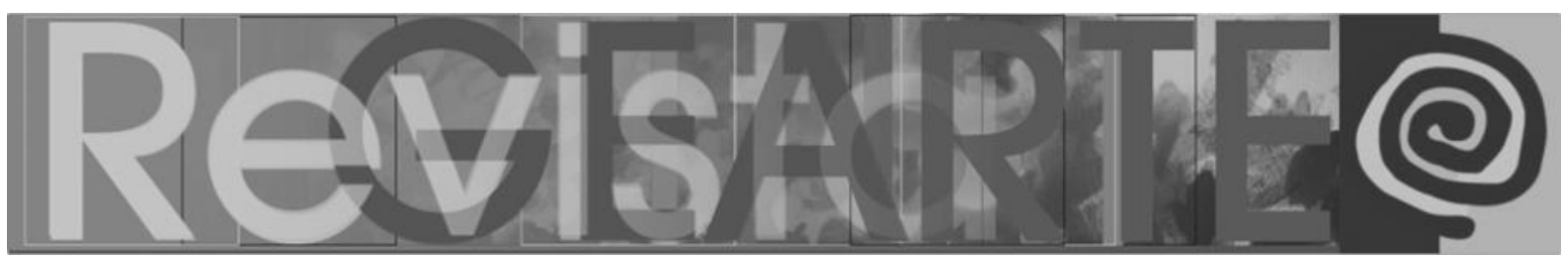

A questão - a problemática - do papel das artes na educação como perpetuador de dualismos e transmissor de formas de exclusão, seria um aspecto a ser explorado em profundidade em um artigo ou em uma monografia. Aqui o deixamos enunciado como um sinal de alerta do que nós nos estamos privando (de nós mesmos) quando - como já acontece no Ocidente - deslocamos o acesso ao simbólico e à imaginação - que é o que nos constitui, como aponta Juan Arnau (2020) em sua Historia de la imaginación. Mas também para reivindicar e não esquecer, como aponta Richard Sennett (2009), que a artesania une "cultura material" e "conhecimento tácito", que são bens de "capital social", ou seja, conhecimentos e habilidades que são acumulados e transmitidos por meio da interação social. Tudo isso constitui um conhecimento corporal do qual parece haver pouca consciência nos países ocidentalizados de hoje. Mas, além disso, promover a presença da arte/artesania na educação, nos lembra, como enseja Sennett (2009), que a motivação básica do artesão é conseguir um trabalho bem feito pela simples satisfação de fazê-lo, resgata uma relação com o material que redefine o sentido da relação entre o humano e o não-humano, e que pode abrir linhas de fuga, como Sennett (2009) continua a apontar, diante da degradação da autoconsciência e da autoestima a que as formas atuais de produção capitalista conduzem.

\section{A proposta desta edição}

Como já assinalamos, na edição da Revista GEARTE que ora apresentamos ao público, é feita referência a um tema importante no contexto artístico, principalmente no sentido de legitimar (sem isentar do debate) manifestações artesanais para além das dicotomias que historicamente se instituem entre arte e artesania.

Assim, levantar a discussão e avançar por meio de propostas que são estabelecidas sob a premissa "O ensino das artes visuais e artesania: experiências e confluências metodológicas" apresenta, no seu âmbito, a intenção de promover 


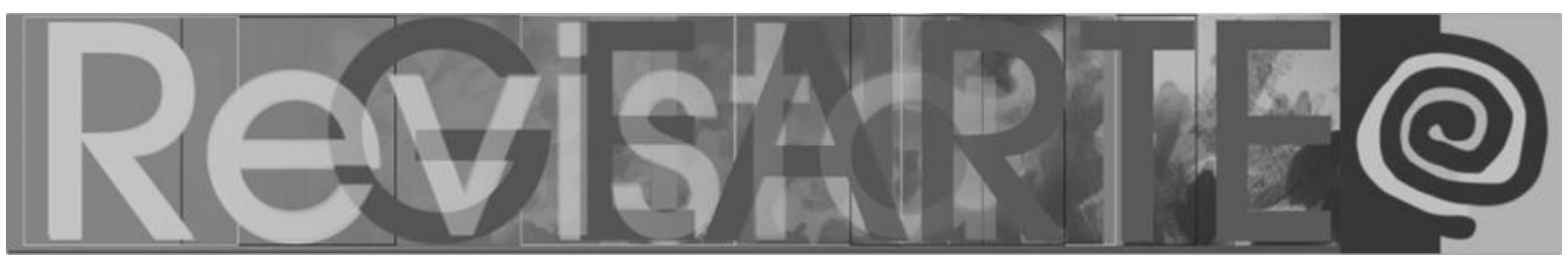

diálogos entre a investigação, reflexões e experiências relacionadas com as artes visuais, o seu ensino e as suas interfaces com a artesania, para situar o campo de investigação proposto por essas abordagens artísticas, delimitando territórios sem, no entanto, estabelecer fronteiras. Nesse sentido, propõe (re)pensar novas formas de assinalar e explorar as possibilidades de expandir as fronteiras e instaurar conexões que permitam situar os quefazeres artesanais - seus proponentes, os processos de reflexão e os seus resultados - em um contexto mais amplo de discussões. Isso significa elucidar a necessidade de fomentar atitudes que exigem e integram esse conhecimento e fazeres com a vida de cada indivíduo.

As analogias da vida como um tecido têm sido metáforas de uso recorrente, narrativas que fazem parte de um imaginário coletivo, pensadas a partir das tramas que são construídas na vida quotidiana, a partir dos fios — os dias - tecidos na urdidura do tempo, nos pontos feitos e desfeitos, pelos desejos e aspirações humanas, nas costuras ou nos bordados, em suma, num universo ilimitado de relações. Como disse Guimarães Rosa: "viver é um rasgar-se e remendar-se" (1968, p. 76), porque esse tecido que é a vida tem a condição de ser costurado, de se regenerar - embora, no final dessa trajetória, possa apresentar as marcas das "rasgaduras e manchas" a que foi submetido e que nele estão circunscritas. Desse mesmo universo parecem emergir as cinco peles descritas pelo artista austríaco Hundertwasser (1928-2000), que tão bem integra e conecta, por meio da arte, o ser humano com a vida e a natureza.

A partir de verbos como tecer, dar forma, fundir, coser, forjar, entre muitos, reivindicados pelo trabalho com as mãos e a cabeça (SENNETT, 2009), a artesania é concebida e ganha materialidade como uma atividade original que tenta promover as relações dialógicas com a própria vida. Tais diálogos podem ter lugar de uma forma solitária, ou seja, apenas entre o sujeito e o objeto da sua obra. Contudo, em muitas situações, são produzidas de forma solidária, sendo construídas em ações interativas e comunitárias entre os sujeitos e os seus feitos, uma vez que o trabalho coletivo é a marca que, de alguma forma, constitui o 


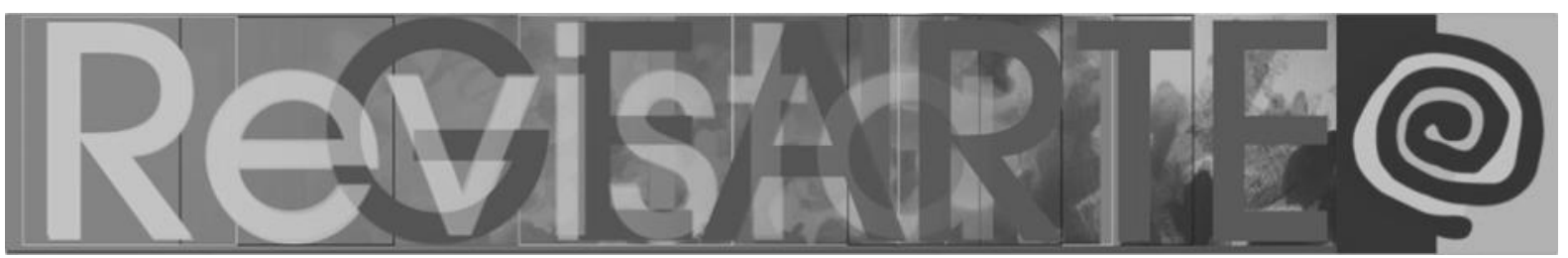

trabalho artesanal na contemporaneidade. Essas artes de bordar, tecer, crochetar e tantos outros e ofícios e manualidades como a nossa imaginação pode nomear, são coletivos - e, na maioria das vezes, conforme já apontamos, femininos.

\section{O conteúdo desta edição}

Este artigo que apresenta a Edição da Revista Gearte, além de propor elementos para pensar e discutir experiências, confluências e derivas em torno da arte e da artesania, apresenta um audiovisual produzido para uma atividade que relaciona esses conceitos a questões de identidade, com base na exposição "Teixint Identitats", cujo texto curatorial, de Carmen Marcos e Ascensión García, também é apresentado neste volume. O projeto, intitulado "Artesaneando Identidades", realizado no primeiro semestre de 2020 com mais de 70 alunos da Escola Oriol Martorell (Barcelona), teve como proposta final um vídeo produzido pelo professor Jesús-Ángel Prieto, que apresentamos aqui (https://vimeo.com/480983805) com algumas declarações explicativas de seu produtor:

Fazer é pensar (SENNETT, 2009), e este pensar fazendo, constitui uma relação intensa entre a mão e o cérebro. E não há hierarquias ali, a mão ensina o cérebro e o cérebro devolve sabedoria e reflexão. Foi séculos depois que o pensamento se tornou hierarquicamente mais poderoso, para não mencionar em nossa era na qual a tecnociência se tornou a nova religião, e a vontade de nos sobressair como seres humanos nos leva a considerar o robô como nossa mais excelente criação. Vamos parar de fazer, isto é a panaceia..., antropologicamente, vamos parar de pensar. $E$ abandonaremos nossas mãos e com elas a matéria, e não estaremos mais no mundo... Mas o mundo é matéria, matéria esgotada, matéria finita que nos lembra os limites ecológicos. A artesania é a nossa revolução, nosso caminho rumo àquela consciência das espécies que nos torna "bons artesãos do meio ambiente".

Sobre essas e outras questões, somos convidados a debater e ampliar a presente reflexão, cuja proposta abre um caminho para acercar-se da arte e da 


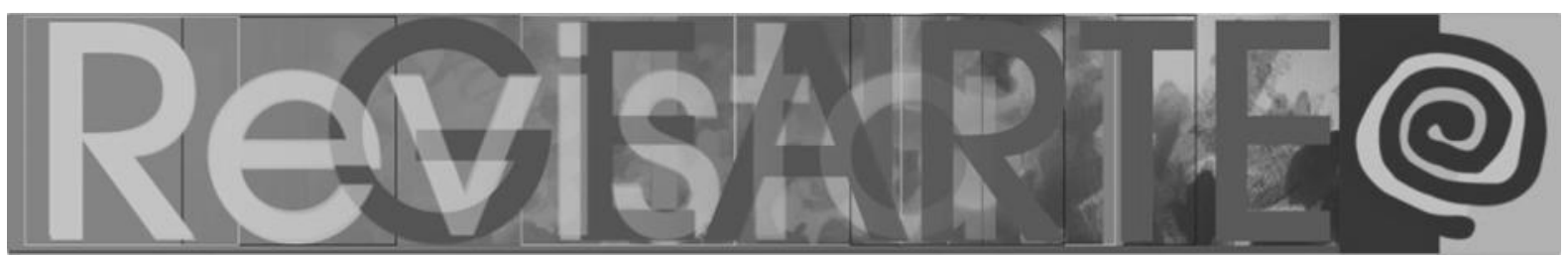

artesania e não apenas para apresentar aspectos sobre a arte ou a artesania, embora seja importante salientar que, neste debate, permanece, muitas vezes, a ideia errada que defende a separação entre artesania e arte, como consequência das dicotomias históricas já apontadas.

Dentro deste volume da Revista GEARTE, o artigo intitulado "Trabajo artesanal, artesanía e industrias creativas: reflexiones en torno a las transformaciones de la actividad socio-cultural", de Daniel Roberto Vega Torres, professor da Fundación Universitaria Juan de Castellanos (Tunja/Boyacá, Colômbia), fornece uma crítica sobre a compreensão da artesania e do trabalho artesanal a partir do desenvolvimento histórico do capitalismo. Suas reflexões contemplam a indústria e a artesania, compreendendo as relações sociais, políticas e simbólicas que oferecem o reconhecimento da emergência da artesania e dos artesãos como expressão cultural. As reflexões conceptuais e políticas definem as trajetórias de estudo e intervenção propostas pelo autor.

No texto de Ana Paula Aparecida Caixeta, professora da Universidade de Brasília (Brasília/DF, Brasil), e Luiz Carlos Pinheiro Ferreira, professor da Universidade de Brasília (Brasília/DF, Brasil), sob o título "Artesania como processo: o estágio curricular nas Artes Visuais como espaço de observação e reflexão", nos é apresentado uma série de diálogos sobre o estágio curricular no campo da observação e da regência nas Artes Visuais. São abordadas questões que transitaram pelo cotidiano formativo em licenciatura, construindo reflexões que atravessaram o estágio e promoveram interfaces com a artesania, comportando discussões de um conhecimento sensível, que pensa a artesania como um processo.

Maria José Delgado Corredera, professora da Universidad de Málaga (Málaga, Espanha), propõe uma experiência baseada nos seus escritos "La artesanía como forma de supervivência. Una historia de vida en tiempos de la postguerra española". A autora assinala que a artesania implica a desconexão da 


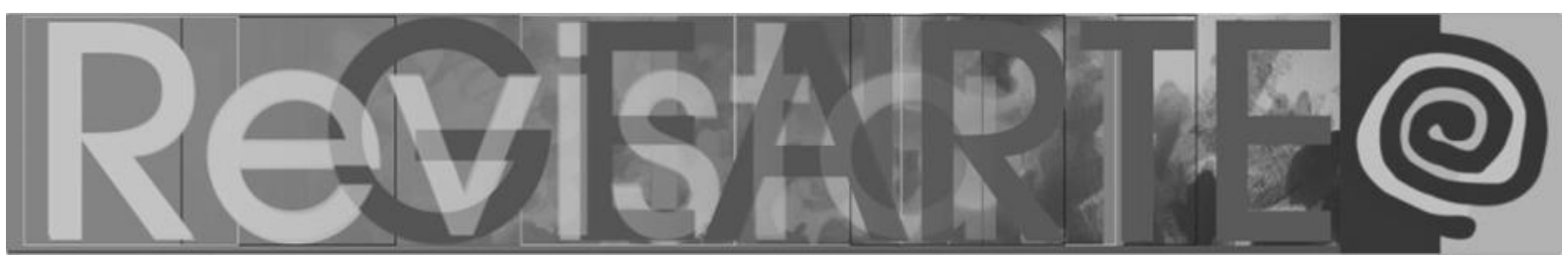

vida externa e a libertação da imaginação, favorecendo um diálogo interno e reflexivo para uma busca pessoal. As histórias de vida, entrelaçadas com a artesania, encontram um significado educativo em ambas. Como uma identidade é construída e como a artesania pode ser experimentada enquanto algo habitual que é aprendido e tem a capacidade de proporcionar a sobrevivência. A partir do presente, a protagonista Electra compreende o seu passado e reflete sobre ele.

Em "Bordaduras na experiência formativa de mulheres camponesas", de Jossier Sales Boleão, doutorando na Universidade Federal de Goiás (Goiânia/GO, Brasil), e Alice Fátima Martins, professora da Universidade Federal de Goiás (Goiânia/GO, Brasil), temos uma experiência desenvolvida com camponesas em oficinas de arpilleras, que configura processos de transformação da maneira como essas mulheres enxergam suas realidades e se conectam com a realidade de outras. Por meio do bordado livre, as possibilidades de diálogos se tecem em objetos artísticos e para além deles, que emergem do individual ao coletivo e se costuram do coletivo para ressignificar o individual, em total relação com o cotidiano que dá luz a memórias e afetos entre as mãos camponesas.

As discussões e conteúdos propostos no artigo de Tales Bedeschi Faria, professor do Instituto Federal de Educação, Ciência e Tecnologia de Minas Gerais (Santa Luzia/MG, Brasil), e Vanginei Leite Silva, mestrando na Universidade Federal de Minas Gerais (Belo Horizonte/MG, Brasil), sob o título "As artes do povo Xakriabá e a escola monoepistêmica: desafios metodológicos" questionam que, 12 anos após a promulgação da Lei n.․⒒645/2008, há provas de que o ensino das histórias e culturas dos povos indígenas do Brasil não foi realizado nas escolas. Como pode a escola pedir ao professor para ensinar uma história e cultura que ele ou ela nunca aprendeu? Com base num diálogo entre um professor do povo Xakriabá e um professor não indígena, são discutidos pontos fundamentais, tais como os conceitos de arte, cultura e educação entre os Xakriabá e a forma como este povo ensina e aprende as suas artes. 


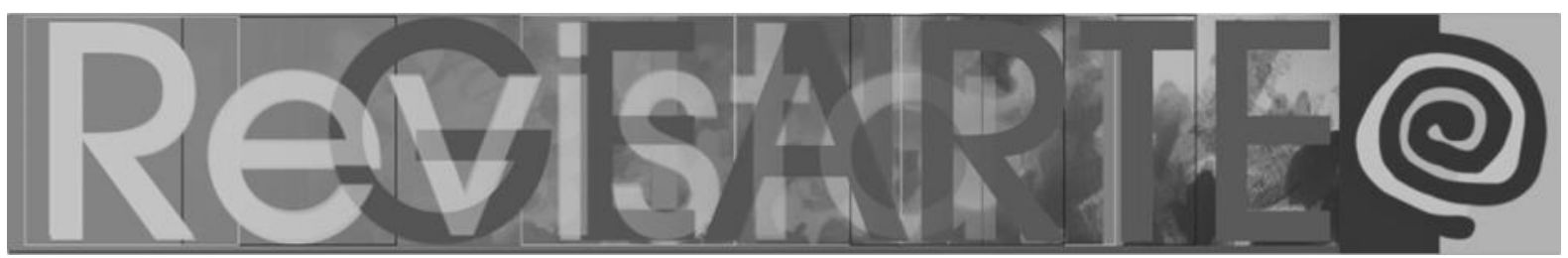

Sob o título "Tejiendo identidades. Un diálogo entre arte y artesanía", das autoras Carmen Marcos Martínez, professora da Universitat Politècnica de València (Valência, Espanha), e Ascensión García, professora da Universitat de Barcelona (Barcelona, Espanha), o artigo apresenta a exposição "Teixint Identitats" (Barcelona/ES), que visava divulgar uma forma específica de fazer arte, reunindo um grupo de 31 artistas para partilhar a utilização de técnicas artesanais próximas às têxteis. Tanto o conteúdo conceitual como as técnicas utilizadas apresentam certa diversidade, explorando questões relacionadas com o gênero, a identidade, o ambiente doméstico ou pessoal, bem como questões sociais e ambientais dentro dessa exposição de arte.

$\mathrm{Na}$ comunidade de Sibaúma, os irmãos mestres do coco de zambê, do grupo Herdeiros de Zumbi, tornam possível a recuperação dessa arte que só existe no Rio Grande do Norte (Brasil). Das mãos talentosas emergem tambores, berimbaus e outros instrumentos utilizados nas rodas de coco e capoeira. $\mathrm{Na}$ artesania necessária para fazer cada instrumento, a combinação do conhecimento local e das matérias-primas com os produtos do comércio popular permite que o coco de zambê exista, se renove e resista. Este é o conteúdo do artigo de Nilton Xavier Bezerra, professor do Instituto Federal de Educação, Ciência e Tecnologia do Rio Grande do Norte (Mossoró/RN, Brasil), intitulado "Processos e reminiscências culturais na produção artesanal de instrumentos de coco de zambê em Sibaúma/RN".

Lurdi Blauth, professora da Universidade Feevale (Novo Hamburgo/RS, Brasil), e Amanda Becker, mestranda da Universidade Feevale (Novo Hamburgo/RS, Brasil), apresentam-nos "Imagens híbridas: intersecções da fotografia com meios litográficos alternativos". Começando pelos passeios por meio do fluxo da vida quotidiana, as imagens são transformadas e ressignificadas, adquirindo outra grandeza, valorizada por um olhar sensível sobre a natureza. Uma produção paisagística denominada "Inços", realizada a partir de fotografia digital e meios analógicos alternativos, busca substituir os materiais tradicionalmente 


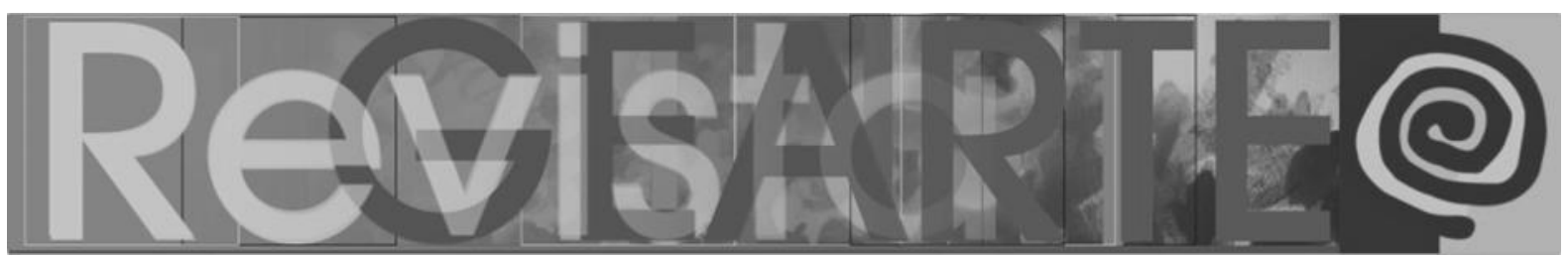

utilizados na litografia. Apresenta alguns dos resultados obtidos pela gravação com refrigerante cola em chapas de offset descartadas pela indústria gráfica e as suas possibilidades de reprodução de imagem.

Ainda temos, nesta edição da Revista GEARTE, dois ensaios visuais: no primeiro intitulado "Tres performances para un país que lucha con arte", Ricard Huerta, professor da Universitat de València (València, Espanha), apresenta três performances, em que os artistas interagiram com as pessoas no espaço público. Essas ações tiveram lugar durante o "II Seminário Internacional sobre Arte / Gênero / Ensino em Tempos de Conservadorismo", realizado no Centro de Artes da Universidade Regional de Cariri — URCA (Crato, Brasil).

Por fim, apresentamos a proposta de Lucía Loren Atienza, professora da Universidad Nebrija e do Instituto Nebrija de Competencias Profesionales (Madri, Espanha), intitulada "Para una cultura material cíclica desde el arte y la artesania". A artista oferece um percurso em imagens a partir do contexto da pesquisa para o desenvolvimento da sua produção artística, que parte do local e dos materiais que o rodeiam, com o propósito de compreender as transformações do desenho da paisagem. Suas intervenções movem-se entre a arte e a artesania, criando diálogos que procuram revalorizar uma cultura material cíclica, utilizando os recursos do próprio território, sem gerar resíduos a outrem.

Queremos agradecer aos autores e às autoras que enviaram artigos para compor este número, aos pareceristas e à artista e professora Dra. Umbelina Barreto pela bela capa.

Esperamos que, diante daquilo que temos salientado, esta edição da Revista GEARTE possa abrir espaço e permitir ao leitor alguns desafios para olhar para essas experiências, confluências e derivas, a partir de outros pontos de vista, procurando alternativas viáveis de diálogo por meio do ensino das artes visuais alicerçadas na artesania e da artesania incorporada às artes visuais. 


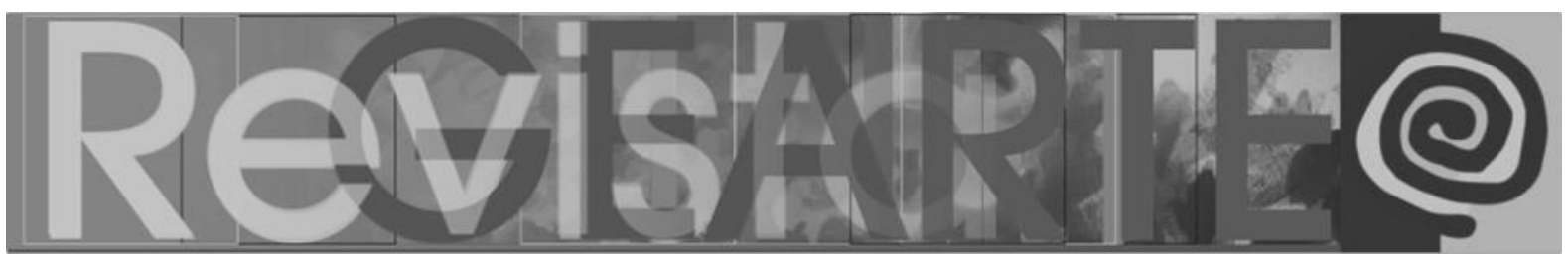

\section{Referências}

ARNAU, Juan. Historia de la imaginación: del Antiguo Egipto al sueño de la ciencia. Barcelona: Planeta, 2020.

ESPEJO, Bea. Aire popular. La artesanía vuelve a ocupar un lugar central en la práctica de muchos artistas que reivindican lo manual como una nueva ideología más allá de los oficios. Babelia, El País, 8 agosto de 2020. Disponível em: <https://elpais.com/cultura/2020/08/03 /babelia/1596456276_484106.html?prm=enviar_email > Acesso em: 5 set. 2020.

FERNÁNDEZ POLANCO, Aurora. Crítica visual del saber solitário. Bilbao: Consonni, 2019.

FREITAG, Vanessa. Resenha do livro La invención del arte: una historia cultural, de Larry Shiner. Alteridades, Cidade do México, v. 25, n. 49 (jan.-jun. 2015): 129-133. Disponível em: <https://alteridades.izt.uam.mx/index.php/Alte/article/view/792>. Acesso em: 10 set. 2020.

SENNETT, Richard. El artesano. Barcelona: Anagrama, 2009.

RIVERA CUSIVANTE, Silvia. Oprimidos pero no vencidos: luchas del campesinado aymara y qhechwa de Bolivia, 1900-1980. Genebra: Instituto de Investigaciones de las Naciones Unidas para el Desarrollo Social — UNRISD, 1986.

RODRÍGUEZ CAMPOMANES, Pedro. El fomento de la industria popular: la educación popular de los artesanos. Oviedo: Grupo Editorial Asturiano, 1991.

ROSA, João Guimarães. Sagarana. Rio de Janeiro: Livraria José Olympio, 1968.

SHINER, Larry. La invención del arte: una historia cultural. Barcelona: Editorial Planeta, 2004.

Dra. Rita Inês Petrykowski Peixe ${ }^{1}$ (Instituto Federal de Santa Catarina — IFSC, Itajaí/SC, Brasil)

Dr. Fernando Hernández-Hernández ${ }^{2}$ (Universitat de Barcelona - UB, Barcelona/España)

Dr. Jesús-Ángel Prieto Villanueva $^{3}$
(Escola Massana, Universitat Autónoma de Barcelona - UAB, Barcelona,
España)
Ma. Rosangela Canônica ${ }^{4}$
(Instituto Federal de Santa Catarina - IFSC, Itajaí/SC, Brasil)
Organizadores do presente número


1 Doutora em Educação pela Universidade Federal do Rio Grande do Sul (UFRGS/Porto Alegre). Mestre em Educação. Especialista em arte-educação. Graduada em Educação Artísticahabilitação em artes plásticas e em Pedagogia-habilitação em Orientação Educacional. Realizou estágio de Pós-Doutorado na Universitat de Barcelona. Professora no Instituto Federal de Santa Catarina - IFSC, Campus de Itajaí. Pesquisadora do Grupo de Pesquisa em Educação e Arte (GEARTE/UFRGS) e coordenadora do Grupo de Investigação Estudos de Imagem, Design, Artesania e Práticas Educativas (DZART/IFSC). Tem experiência em ensino, pesquisa e extensão com ênfase em: métodos e técnicas de ensino, estudos culturais e cultura visual, ensino da arte, formação de professores, design social, economia solidária e artesania. Email: ritapeixe@hotmail.com

2 É professor doutor e atua na Unidade de Pedagogia Cultural da Faculdade de Belas Artes da Universitat de Barcelona. É membro da REUNID, do grupo de pesquisa consolidado Esbrina e do grupo de inovação docente Indaga't. Realiza projetos ligados à Investigação Baseada nas Artes, no giro pós-qualitativo, nos novos materialismos e na abordagem das cartografias como epistemologia e metodologia. É autor de inúmeros livros, já traduzidos no Brasil. E-mail: fdohernandez@ub.edu

3 É licenciado em História da Arte (1977) pela Universitat Autónoma de Barcelona, e Doutor (2017) pela Universitat de Barcelona, com a tese "La lucha por el reconocimiento de los oficios artísticos y la Escola Massana de Barcelona. El caso de los esmaltes, la cerámica y la joyería". Ministrou classes na Escola Massana, Centro de arte y diseño de Barcelona (vinculado a Universitat Autónoma de Barcelona) desde 1979, foi diretor deste Centro durante o período 1993-2000. Instaurou e coordenou o curso de Postgrado en Artes Aplicadas Contemporáneas (2014-2019). Presidio o A FAD (Artistas y artesanos del Fomento de las Artes y el Diseño) durante o período de 2003-2007. Promoveu e coordenou as jornadas sobre artesania contemporânea IBERIONA (2003 a 2009), participou em Conselhos Assessores de diferentes governos no âmbito da artesania e do design, escreveu artigos e ministrou conferências sobre esses temas. www.jesusangelprieto.eu E-mail: jesusangel.prieto@escolamassana.cat

4 Mestre em Design, com ênfase em Produção do Design e Contexto Sociocultural (UNIVILLE, 2013). Graduada em Design de Produto (UNIVILLE, 2004). Possui experiência profissional em Design Social, tendo atuado em projetos de Geração de Trabalho e Renda voltados ao empreendedorismo popular. Por meio de metodologia social em design, capacitou comunidades criativas, dando ênfase aos processos participativos para o desenvolvimento de produtos. Atualmente, integra o grupo de Pesquisa DZART: Estudos de Imagem, Design, Artesania e Práticas Educativas (IFSC), buscando investigar possibilidades metodológicas do design e seu uso em processos de artesania. Tem experiência em processos de artesania nos contextos de alimentação, agricultura familiar e sistema prisional, atuando com Educação Popular, Gênero e Economia Solidária, principalmente, nos seguintes temas: Empreendedorismo, Protagonismo Social, Autogestão Criativa, Estética, Desenvolvimento de Produtos e Gestão Produtiva. E-mail: canonicarosangela@gmail.com 